\section{THE ROLE OF COMMUNITY LIBRARY RUMAH ASA IN EMPOWERMENT OF COMMUNITIES IN KARANGKAJEN YOGYAKARTA}

\section{PERAN TBM RUMAH ASA DALAM PEMBERDAYAAN DI KARANGKAJEN YOGYAKARTA}

Jurnal Pendidikan Luar Sekolah

http://kolokium.ppj.unp.ac.id/ Jurusan Pendidikan Luar Sekolah

Fakultas Ilmu Pendidikan

Universitas Negeri Padang

Sumatera Barat, Indonesia

Volume 8, Nomor 1, April 2020

DOI: $10.24036 /$ kolokium-pls.v8i1.390

\author{
Nurul Hayati1,2 \\ 1Jurusan Pendidikan Luar Sekolah Fakultas Ilmu Pendidikan Universitas Negeri Padang \\ 2Email: nurul.yoga27@gmail.com
}

\begin{abstract}
Community Library is an institution that provides various types of learning materials needed by the community. TBM As a place for organizing the ability to read and learn, as well as a place to get information for the community. One of the TBMs carrying out these activities is Rumah Asa TBM. In addition to disseminating information, TBM Rumah Harapan also plays a role in community empowerment. This paper describes community empowerment carried out by Taman Bacaan Masyarakat. To obtain these data this paper uses a literature study in the form of conceptual studies. The role of TBM Rumah Asa in community empowerment includes hand skills for mothers, asakura shops, mukena asakura, and Eco.J print.
\end{abstract}

Keywords: Community Library, Community Empowerment

\begin{abstract}
ABSTRAK
Taman Bacaan Masyarakat adalah lembaga yang menyediakan berbagai jenis bahan belajar yang dibutuhkan oleh masyarakat. TBM Sebagai tempat penyelenggaraan pembinaan kemampuan membaca dan belajar, sekaligus sebagai tempat untuk mendapatkan informasi bagi masyarakat. Salah satu TBM yang melaksanakan kegiatan tersebut adalah TBM Rumah Asa. Selain menyebarkan informasi, TBM rumah asa turut berperan dalam pemberdayaan masyarakat. Tulisan ini menggambarkan pemberdayaan masyarakat yang dilakukan oleh Taman Bacaan Masyarakat. Untuk memperoleh data tersebut tulisan ini menggunakan studi literature yang berupa kajian konseptual. Adapun peranan TBM Rumah Asa dalam pemberdayaan masyarakat diantaranya adalah keterampilan tangan untuk ibu-ibu, toko asakura, mukena asakura, dan Eco.J print.
\end{abstract}

Kata Kunci: TBM, Pemberdayaan Masyarakat 
The Role of Community Library Rumah Asa in Empowerment of Communities...

\section{PENDAHULUAN}

Daerah Istimewa Yogyakarta adalah salah satu kota yang menjadi tujuan pembelajar dalam mengecap pendidikan Hal ini dikarenakan oleh keistimewaan dan keunikan kotanya. Selain itu, keistimewaan Yogyakarta yang harus dipertahankan adalah predikat sebagai kota pendidikan. Gemar membaca seharusnya menjadi ciri khas yang melekat dan selalu menghiasi aktivitas keseharian masyarakatnya. Banyak informasi mengenai ilmu pengetahuan yang dapat diperoleh dari membaca. Sebagaimana kita ketahui salah satu faktor penyebab terjadinya masalah-masalah sosial, seperti kemiskinan, keterbelakangan dan kebodohan adalah karena tidak mampu mengakses informasi dan juga karena tingkat pendidikan masyarakat yang sangat rendah. Akibatnya mereka sulit untuk memperoleh pekerjaan yang layak karena kualitas sumber daya manusia yang tidak memadai. Oleh karena itu, upaya pengentasan terhadap masalah-masalah sosial harus dilakukan secara komprehensif, mencakup berbagai aspek kehidupan masyarakat dan dilaksanakan secara terpadu.

Pemerintah telah berupaya dalam melaksanakan kegiatan pemberdayaan masyarakat. Hal ini tercantum dalam Intruksi Presiden Nomor 5 tahun 2006 tentang Gerakan Nasional Percepatan Penuntasan Wajib Belajar Pendidikan Dasar Sembilan Tahun dan Pemberantasan Buta Aksara (GNP-PWB/PBA) yang telah ditindaklanjuti dengan Peraturan Teknis Pelaksanaan GNP-PWB/PBA dan Prakarsa Keasaraan Untuk Pemberdayaan (LIFE) UNECO-UNLD (Presiden Republik Indonesia, 2006). Salah satu upaya pemerintah adalah dengan mendekatkan masyarakat dengan buku sebagai sumber belajar. Hal ini dapat diwujudkan melalui pendirian dan pengembagan Taman Baca Masyarakat (TBM) di tengahtengah masyarakat.

TBM bila dilihat dari fungsinya sebenarnya sama saja dengan perpustakaanperpustakaan umum, namun bedanya perpustakaan sudah dilengkapi dengan sarana, seperti gedung, koleksi sarana yang sudah memadai serta sudah dikelola dengan tenaga yang memang berasal dari pendidian ilmu perpustakaan, sedangkan Taman Bacaan Masyarakat kebanyakan belum memiliki sarana seperti gedung permanen koleksi yang memadai dan masih dalam bentuk dikelola oleh pribadi-pribadi. Selain itu, TBM memang lebih bervariasi dibandingkan perpustakaan, kita mungkin sudah mengetahui, dalam sautu perpustakan sering diberlakukan prosedural dan peraturan yang harus dilakukan, karena memang perpustakaan sendiri merupakan instansi resmi dari pemerintah yang ada anggaran secara khusus, sedangkan TBM adalah suatu lembaga non formal, dikelola dengan dana swadaya dan biasanya tidak diberlakukan peraturan-peraturan khusus seperti di perpustakaan. TBM memang terkesan longgar, siapapun tanpa terkecuali dapat mengakses bahan pustaka dalam keadaan apapun, baik memakai sendal sepat, bahkan tidak memakai alas kaki pun tidak menjadi masalah. TBM memang terkesan lebih merakyat dan lebih dekat dibandingkan dengan perputakaan.

Kehadiran TBM yang tumbuh dari, untuk dan oleh masyarakat diharapkan dapat "mempercepat" pengembangan budaya baca masyarakat. Dengan adanya TBM sebagai sumber belajar masyarakat memiliki kedudukan strategis dalam mengembangkan potensi masyarakat (Solfema, Bartin, \& Pamungkas, 2019). Masyarakat dapat melakukan proses pendidikan informal sepanjang hayat melalui fasilitas yang disediakan dan kegiatan yang diselenggarakan oleh TBM (Nuswantara, 2018; Septiarti \& Mulyadi, 2009). Keberadaannya di tengah-tengah masyarakat ini diharapkan mampu mendorong dan mempercepat terwujudnya masyarakat belajar (learning society) (Damayani, Silvana, Saepudin, \& Budiono, 2017; Munir \& Hidayatullah, 2019). Artinya masyarakat yang gemar membaca, melek informasi dan mampu 
meningkatkan daya saing di era kompetitif sehingga masyarakat terbebas dari kemiskinan dan keterbelakangan dan kebodohan.

TBM Rumah Asa sangat ramai dikunjungi oleh masyarakat terutama pada sore hari. Banyak anak-anak maupun remaja yang mampir untuk melihat daftar koleksi bacaan TBM dan melihat produk keterampilan yang diperjualbelikan pada warung yang berada di TBM tersebut. Pada hari-hari tertentu, TBM Rumah Asa juga sering mengadakan kegiatan-kegiatan yang menarik perhatian masyarakat, seperti pesta ice cream, kegiatan keterampilan, workshop, dan lain-lain

Berdasarkan hal di atas, maka penulis tertarik untuk menulis apa dan bagaimana peran TBM Rumah Asa dalam pemberdayaan masyarakat di Desa Karangkajen. Penulis berharap dengan adanya tulisan ini dapat memberi masukan bagi penulis sebagai orang yang bergerak di bidang pendidikan nonformal maupun bagi masyarakat luas yang memerlukan informasi ini.

\section{METODE}

Metode yang digunakan dalam artikel ini adalah studi kepustakaan. Penulis mengumpulkan berbagai referensi terkait topik melalui buku, artikel jurnal, dan lainnya. referensi tersebut dibaca secara menyeluruh untuk mendapatkan informasi yang tepat mengenai peran TBM Rumah Asa dalam pemberdayaan masyarakat di Karangkajen Kota Yogyakarta.

\section{HASIL PENELITIAN DAN PEMBAHASAN}

\section{Taman Bacaan Masyarakat}

Menurut Kalida (2012) Taman Bacaan Masyarakat adalah suatu lembaga yang melayani kebutuhan masyarakat akan informasi mengenai ilmu pengetahuan dalam bentuk bahan bacaan dan bahan pustaka lainnya. Adapun pengelola dari TBM adalah masyarakat yang dipercaya dan mau berpartisipasi dalam kegiatan TBM. Biasanya masing-masing TBM memiliki kegiatan-kegiatan tersendiri untuk menarik minat baca masyarakat.

Taman Bacaan Masyarakat adalah lembaga yang menyediakan berbagai jenis bahan belajar yang dibutuhkan oleh masyarakat. Sebagai tempat penyelenggaraan pembinaan kemampuan membaca dan belajar, sekaligus sebagai tempat untuk mendapatkan informasi bagi masyarakat (Hapsari, 2016). Penyelenggaraan TBM bukan hanya untuk mengumpulkan dan menyimpan bahan-bahan pustaka, tetapi dengan adanya Taman Bacaan Masyarakat diharapkan dapat membantu warga belajar dalam menimba ilmu pengetahuan, keterampilan yang dibutuhkan warga belajar dalam kehidupannya. Agar dapat menunjang masyarakat dan warga belajar gemar membaca, maka dalam pengadaan bahan bacaan di TBM harus mempertimbangkan selera dan kebutuhan warga belajar (Hapsari, 2016).

Menurut Hatimah \& Sadri (2008) TBM merupakan sebuah lembaga yang menyediakan bahan bacaan yang dibutuhkan oleh masyarakat sebagai tempat untuk mendapatkan informasi bagi masyarakat, khususnya yang bersumber dari bahan pustaka. Bahan pustaka merupakan semua jenis bahan bacaan dalam berbagai bentuk media. Taman bacaan masyarakat menyediakan bahan bacaan yang dibutuhkan masyarakat. Bahan bacaan dapat berupa bahan bacaan cetak maupun non cetak (elektronik). Menurut Ludwig \& Starr 
The Role of Community Library Rumah Asa in Empowerment of Communities...

(2005) menjelaskan library as place is phisycal building which provides storage and access to information resources in material format as well as electronically and provides space for individual and group activity. Hal ini dapat dijelaskan perpusatakaan sebagai tempat atau bangunan fisik yang menyediakan penyimpanan dan akses ke sumber informasi dalam format materi serta elektronik dan menyediakan ruang untuk kegiatan individu dan kelompok.

Sebagai institusi yang memiliki koleksi pengetahuan melalui koleksi buku yang disediakan, TBM perlu berupaya agar masyarakat tertarik untuk mengunjungi TBM tersebut. Untuk itu pengelola TBM perlu membuat kegiatan yang dapat menarik perhatian masyarakat, antara lain sosialisasi melalui organisasi-organisasi masyarakat yang ada, membuat leaflet sebagai alat promosi, mengupayakan agar selalu terjadi sirkulasi buku, menyediakan bahan bacaan atau bahan informasi yang dibutuhkan oleh masyarakat, menyediakan bahan bacaan yang merangsang keingintahuan masyarakat, mengadakan berbagai jenis lomba bagi pengujung, memberikan penghargaan kepada pengunjung setia, mengupayakan kelengkapan TBM dengan media belajar lain (TV, APE, dll), mendesain TBM sebagai tempat yang menarik untuk didatangi dan menyediakan tempat yang nyaman dan santai untuk membaca.

Berdasarkan hasil penelitian yang dilakukan oleh Rachmawati \& Winoto (2017) menyatakan bahwa dengan adanya Taman Bacaan Masyarakat (TBM) anak-anak mulai tumbuh minat bacanya. Hal ini terlihat dengan mulainya banyak anak-anak yang datang ke taman bacaan masyarakat, sedangkan bagi masyarakat remaja dan dewasa hadirnya TBM sangat bermanfaat karena selain menyediakan bahan bacaan juga kerap menyediakan bahan bacaan yang dibutuhkan juga kerap kali menyelenggarakan kegiatan diskusi dan pelatihan. Dari hasil penelitian tersebut dijelaskan manfaat TBM yang dirasakan oleh masyarakat, mulai dari kalangan anak-anak hingga kalangan dewasa.

Menurut Wardah (2019) tujuan TBM adalah memberikan akses sebesar-besarnya kepada masyarakat sebagai pusat pembelajaran dan budaya membaca, menimbulkan kecintaan membaca, membina kreativitas di bidang seni dan budaya, meningkatkan ekonomi masyarakat, meningkatkan keahlian masyarakat meningkatkan pengetahuan tentang teknologi, mengembangkan potensi anggota di bidang bahasa, menjalin komunikasi antar TBM dan masyarakat, pusat kegiatan belajar dan menjadi pusat informasi, serta meningkatkan kualitas hidup masyarakat.

Dengan Program kegiatan TBM ini diharapkan nantinya dapat mewujudkan masyarakat gemar belajar (learning society) dengan salah satu indikatornya berupa masyarakat gemar membaca (reading society). TBM juga menjadi sarana pendukung yang cukup efektif dalam pemberantasan buta aksara. Ini dilakukan dengan memberikan layanan pendidikan nonformal bagi masyarakat. Sejauh ini TBM yang ada belum dimanfaatkan secara maksimal dan optimal oleh masyarakat. Sebagian TBM yang kurang diminati oleh warga belajar lebih pada karena pengelolaan yang kurang maksimal dan kurangnya motivasi masyarakat untuk membaca.

\section{Pemberdayaan Masyarakat}

Pemberdayaan masyarakat merupakan proses pembangunan yang mana masyarakat memiliki inisiatif untuk memulai proses kegiatan sosial untuk memperbaiki situasi dan kondisi diri sendiri (Pamungkas, 2016). Pemberdayaan masyarakat dapat terjadi apabila masyarakat itu sendiri ikut pula berpartisipasi. Pemberdayaan masyarakat merupakan salah satu program dari masyarakat dan untuk masyarakat guna memberikan daya atau kemampuan tertentu dengan tujuan untuk meningkatkan kualitas hidup masyarakat yang lebih baik dalam segala bidang. Pemberdayaan masyarakat dapat dilakukan melalui komunitas-komunitas atau 
kelompok-kelompok yang ada di masyarakat. Pemberdayaan masyarakat berawal dari konsep atau kata pemberdayaan (Yuliyanto \& Irhandayaningsih, 2019).

Pemberdayaan masyarakat bertujuan untuk membangun sebuah komunitas yang berdaya dan mampu bersaing serta berpartisipasi di tengah masyarakat. Hal ini senada dengan apa yang dikatakan oleh Laverack (2005) bahwa "to build more empowered or capacity-rich communities such that a programme, 1) Improves participation; 2) Develops local leadership; 3) Increases problem assessment capacities; 4) Enhances the ability to 'ask why; 5) Builds empowering organizational structures; 6) Improves resource mobilization; 7) Strengthens links to other organizations and people; 8) Creates an equitable relationship with outside agents; 9) Increases control over programme management.

Dari penjelasan di atas dapat diartikan bahwa pemberdayaan masyarakat berperan untu meningkatkan partisipasi masyarakat, mengembangkan kepemimpinan, meningkatkan kapasitas penilaian masalah, meningkatkan kemampuan bertanya (rasa ingin tahu), memberdayakan struktur organisasi, meningkatkan mobilisasi sumber daya, memperkuat tautan ke organisasi dan orang lain, membuat hubungan yang adil, serta meningkatkan kontrol atas manajemen program. Menurut Sutawa (2012) menyatakan "Empowerment concept arises as an effort to give local community or marginal people to quit from voicelessness and powerlessness condition”. Hal ini dapat diartikan bahwa konsep pemberdayaan muncul sebagai upaya untuk memberikan kepada komunitas lokal atau marginal orang untuk berhenti atas kondisi ketidakharapan dan ketidakberdayaan.

Terdapat empat prinsip yang sering kali digunakan untuk suksesnya program pemberdayaan, yaitu prinsip kesetaraan, partisipasi, berkelanjutan dan keswadayaan atau kemandirian. Adapun keterangan dari prinsip pemberdayaan masyarakat, yaitu pertama, prinsip kesetaraan. Prinsip kesetaraan merupakan prinsip utama yang harus dipegang dalam proses pemberdayaan masyarakat ialah adanya kesetaraan kedudukan antara masyarakat dengan lembaga yang melakukan program-program pemberdayaan masyarakat, baik itu lakilaki maupun wanita. Dinamika yang dibangun, yakni hubungan kesetaraan atau kesejajaran dengan mengembangkan mekanisme berbagai pengetahuan, pengalaman, serta keahlian satu dengan yang lain. Masing-masing saling mengakui kelebihan dan kekurangan, sehingga terjadi proses saling belajar mengajar. Kedua, prinsip partisipasi. Program pemberdayaan yang akan menstimulasi kemandirian masyarakat, yakni program yang sifatnya partisipatif, direncanakan, dilaksanakan, diawasi dan dievaluasi oleh masyarakat. Namun agar sampai pada tingkatan tersebut perlu waktu dan proses pendampingan yang melibatkan pendamping yang berkomitmen terhadap pemberdayaan masyarakat. Ketiga, prinsip berkelanjutan. Program pemberdayaan harus dirancang/disusun sedemikian mungkin agar berkelanjutan, walaupun di awalnya peran pendamping lebih dominan daripada masyarakat sendiri. Tetapi perlahan-lahan tanpa pasti, peran pendamping akan berkurang, bahkan pada akhirnya dihapus karena masyarakat telah mampu mengelola kegiatannya sendiri. Keempat, prinsip keswadayaan atau kemandirian. Prinsip keswadayaan, yakni menghargai dan mengutamakan kemampuan masyarakat dari pada bantuan pihak lain. Akan tetapi konsep ini tidak melihat kepada orang miskin sebagai objek yang tidak berkemampuan "the have not", tetapi sebagai subjek yang memiliki kemampuan sedikit "the have little".

\section{Peran TBM Rumah Asa dalam Pemberdayaan Masyarakat}

Masyarakat di lingkungan Karangkajen Yogyakarta mengenal Rumah Asa, yaitu sebagai Taman Baca Masyarakat (TBM) gratis. Setiap sore anak-anak prasekolah hingga usia lanjut memenuhi teras untuk membaca. Di TBM Rumah Asa banyak aktivitas yang dilakukan, seperti kegiatan membaca yang diikuti oleh anak-anak. Di TBM tersebut anak- 
The Role of Community Library Rumah Asa in Empowerment of Communities...

anak bisa memperoleh banyak teman baru, berbagi cerita, dan di TBM juga tersedia permainan anak-anak. TBM Rumah Asa berdiri berawal dari banyaknya anak-anak yang berkumpul di Rumah Asa tersebut. Baik itu hanya sekedar berkumpul dan bermain maupun membaca buku yang memang telah tersedia di rumah tersebut. Hal ini menjadi ide bagi pemilik rumah asa untuk menjadikan rumah tersebut sebagai taman bacaan yang menyenangkan. Dan ide ini disambut baik oleh masyarakat sekitar, dibuktikan dengan membludaknya masyarakat yang mendaftar menjadi anggota yaitu sebanyak 1.500 orang. Adapun luas ruangan Rumah Asa adalah 5 × $6 \mathrm{~m} 2$, meskipun tidak terlalu luas pemilik TBM rumah asa mendesain ruang baca tersebut dengan menarik sehingga tetap terlihat cantik dan menawan.

Rumah Asa adalah sebuah wadah sosial non profit yang bergerak dalam kampanye literasi. Cinta Baca dan Cinta Buku adalah menu utamanya. Berdiri sejak tanggal 23 April 2009, bertepatan dengan Hari Dongeng se-Dunia. Dengan harapan, masa depan indah bersemai dalam balutan harapan, ikhtiar dan daya juang utamanya. Walaupun sekian lama berjalan pemilik pasangan suami-istri ini berpikir tidak mungkin selamanya menjadi volunteer atau relawan yang tidak mendapatkan benefit. Sesuai visi misi nama Rumah Asa yang mana ASA adalah singkatan dari Adil dan Sejahtera. Terbentuklah Toko Asakura singkatan dari Adil Sejahtera Omset rata-rata toko ini antara 14-25 juta. Namun sekarang sudah mulai fokus pada mukena dan produksinya. Para relawan juga ikut andil dan mempunyai keterampilan dalam membuat mukena-mukena cantik. Mereka membuat mukena bercerita yang dikombinasi dari katun, rayon, dan felt.

Sejak berdiri hingga Akhir Desember 2014, Rumah Asa memiliki warga baca sejumlah 1.688 orang. Dengan prosentase, 30\% usia PAUD dan TK, 20\% usia SD dan SLTP, 35\% usia Remaja hingga Kuliah (S1), 15\% usia bekerja hingga Lansia. Alhamdulillah koleksi buku pun bertambah dari hibah bersama sejumlah 700 judul, hingga sekarang hampir 17.000 judul. Jangkauan Pembaca rutin ini pun meliputi Imogiri, Kulon Progo juga Sleman.

TBM ini pun rutin mengadakan kegiatan-kegiatan sesuai dengan need assesment masyarakat. Di lini ibu-ibu ada Parenting Class rutin pekan kedua pada setiap bulan yang biasa disebut dengan TIARA (Training Ibunda Rumah Asa), ada Asakura Jelita di pekan ketiga, untuk kajian dan training lifeskill para remaja putri. Kelas Rajut, Kelas Perca, Kelas Kristik, Kelas Flanel, Kelas Ronce juga Kelas Quilling. Ibu-ibu yang mengikuti kelas keterampilan ini juga dapat menitipkan hasil karyanya di Toko Asakura untuk dijual. Selain itu, di lini anakanak Ada Cakruk Hebat yang berisi menggambar, mewarnai, orasi cinta baca, orasi cinta buku, pudding class, beverage class, pesta ice cream, dongeng juga origami. Khusus untuk bapakbapak ada namanya juga kepala keluarga, harus mempunyai visi yang kuat dalam membawa bahtera keluarga, di sini rutin kajian pekanan dan per tiga bulanan ada semacam sarasehan dan semuanya gratis.

Rumah Asa buka dari Senin sampai Jum'at untuk masyarakat. Pengguna bisa leluasa meminjam segala jenis buku yang setiap bulan selalu up to date. Dengan aktifitas yang hampir setiap hari, TBM Rumah Asa berpikir untuk mandiri dengan kreatifitas pada 13 Mei 2012. Kemudian lahir Mukena Literasi pertama di dunia, dengan label Mukena Asakura. Awalnya untuk anak-anak, namun ternyata yang remaja dan para ibu-ibu pun menyukai produk ini, hingga lahirlah Mukena Murah Asakura yang sudah memiliki brand dan digemari tak kurang dari 4.250 orang. Selanjutnya dari Asakura Flanel Rumah Asa merancang dan membangun budaya menabung dan berbagi melalui kencleng atau sebagian orang mengatakan celengan. Dengan mengusung brand Unique dan limited sudah hampir 4.000 kreasi yang betul-betul 
berbeda satu sama lain kami produksi. Ini merupakan hasil kreativitas tangan dingin dari tak lain adalah warga baca Rumah Asa sendiri. ASAKURA, kepanjangan dari: Asa ku raih.

Saat sekarang ini TBM Rumah Asa membuat sebuah kegiatan yang sangat menarik dan diminati oleh masyarakat lokal maupun nasional. Adapun nama kegiatnanya adalah Eco.J Print. Kegiatan tersebut adalah sejenis kegiatan membatik yang dilakukan dengan memanfaatkan bahan alam, yaitu berupa daun-daun dari tumbuhan. Berbagai macam daun yang kering dapat diolah dan dilukis menjadi lukisan yang menarik pada sebuah kain. Hal ini menghasilkan produk kain yang berkualitas dengan gambar-gambar alami dari daun dan tumbuhan. Produk Eco.J print ini sudah melalang buana ke berbagai negara. Bahkan produk kain tersebut telah digunakan oleh para model Indonesia yang ditayangkan oleh salah satu stasiun televisi nasional.

Berdasarkan hal tersebut, maka tak heran jika tagline Rumah Asa adalah "BACA, BERDAYA BERSAMA". TBM Rumah Asa sejak awal berdirinya telah memiliki programprogram yang berperan membantu masyarakat dalam melayani kebutuhan akan informasi mengenai ilmu pengetahuan dalam bentuk bahan bacaan dan bahan pustaka lainnya. Masyarakat dapat melakukan untuk mengakses pendidikan. Pendidikan yang berkualitas dan berkpribadian akan mampu menghasilkan manusia yang berkualitas dan berkepribadian. Kemudian dari pada itu, pendidikan harus menjadi prioritas dalam setiap program pembangunan. Pada saat ini, masih banyak orang yang beranggapan bahwa pendidikan hanya dapat diperoleh melalui bangku sekolah (sekolah formal). Anggapan tersebut tentu tidak benar, karena pendidikan dapat ditempuh baik melalui jalur formal maupun jalur pendidikan nonformal.

\section{KESIMPULAN}

Berdasarkan penjelasan pada pembahasan di atas, maka dapat disimpulkan TBM Rumah Asa telah melakukan kegiatan pembelajaran melalui literasi, penyebaran informasi dan pemberdayaan masyarakat. Kegiatan tersebut dapat dimanfaatkan oleh masyarakat sekitar untuk belajar dan juga dapat menambah penghasilan mereka. Selain itu melalui TBM rumah asa, dapat membuka lowongan pekerjaan baru bagi masyarakat dengan kegiatan penjualan yang dilakukan secara luring maupun daring. Hal ini tentu dibutuhkan tenaga pemasaran yang profesional di bidangnya. Adapun saran dan harapan yang dapat penulis berikan adalah hendaknya TBM Rumah Asa terus berkembang dan mengepakkan sayapnya, sehingga dapat menjadi wadah belajar yang produktif bagi masyarakat.

\section{DAFTAR RUJUKAN}

Damayani, N. A., Silvana, T., Saepudin, E., \& Budiono, A. (2017). Pengembangan Taman Bacaan Masyarakat di Desa Sindangkerta Kecamatan Cipatujah Kabupaten Tasikmalaya. Dharmakarya: Jumal Aplikasi Ipteks Untuk Masyarakat, 6(1), 57-61. Retrieved from http://jurnal.unpad.ac.id/dharmakarya/article/download/14869/7882

Hapsari, M. I. (2016). Kajian Manajemen Taman Bacaan Masyarakat (TBM) di Kabupaten Semarang. Akrab, 7(1), 104-119. https://doi.org/https://doi.org/10.26499/jurnalakrab.v7i1.137

Hatimah, I., \& Sadri. (2008). Pembelajaran Berwawasan Kemasyarakatan. Jakarta: Universitas 
The Role of Community Library Rumah Asa in Empowerment of Communities...

Terbuka.

Kalida, M. (2012). Fundraising Taman Bacaan Masyarakat. (Rumi astuti, Ed.) (4th ed.). Yogyakarta: Cakruk Publishing.

Laverack, G. (2005). Using a "domains" approach to build community empowerment. Community Development Journal, 41(1), 4-12. https://doi.org/10.1093/cdj/bsi038

Ludwig, L., \& Starr, S. (2005). Library as Place: Results of a Delphi Study. Journal of the Medical Library Association, 93(3), 315-326. Retrieved from https://www.ncbi.nlm.nih.gov/pubmed/16059421

Munir, S., \& Hidayatullah, A. (2019). Peran Taman Bacaan Masyarakat (TBM) dalam Meningkatkan Minat dan Budaya Baca di Kabupaten Ciamis. Jurnal Literasi, 3(1), 2329. https://doi.org/http://dx.doi.org/10.25157/literasi.v3i1.2004

Nuswantara, K. (2018). Photo-Voice: Optimalisasi Peran Taman Baca Masyarakat (TBM) sebagai Sarana Penguatan Literasi dan Pengembangan Laboratorium Pembelajaran Sepanjang Hayat. IPTEK Journal of Proceedings Series, 5, 90-97. https://doi.org/http:/ /dx.doi.org/10.12962/j23546026.y2018i5.4427

Pamungkas, A. H. (2016). Pengembangan Program Kuliah Kerja Nyata untuk Pemberdayaan Masyarakat Desa. In Prosiding Seminar Nasional Kompetensi Pendamping Pembangunan Desa Jurusan Pendidikan Luar Sekolah Fakultas Ilmu Pendidikan Universitas Negeri Padang (pp. 51-62). Padang: UNP Press.

Presiden Republik Indonesia. Intruksi Presiden tentang Gerakan Nasional Percepatan Penuntasan Wajib Belajar Pendidikan Dasar Sembilan Tahun dan Pemberantasan Buta Aksara (GNP-PWB/PBA), Pub. L. No. 5 (2006). Indonesia.

Rachmawati, T. S., \& Winoto, Y. (2017). Pengembangan Model Literasi Informasi Kesehatan bagi Masyarakat Nelayan di Kabupaten Pangandaran (Laporan Penelitian). Sumedang.

Septiarti, S. W., \& Mulyadi, M. (2009). Pengembangan Budaya Baca Melalui Taman Bacaan Masyarakat (TBM) yang Berorientasi pada Kebijakan Pembangunan Pendidikan Non Formal dan Informal. Jurnal Penelitian Ilmu Pendidikan, 2(1), 1-13. Retrieved from https://media.neliti.com/media/publications/124129-ID-pengembanganbudaya-baca-melalui-taman-b.pdf

Solfema, S., Bartin, T., \& Pamungkas, A. H. (2019). Community Reading Park Development Training (TBM). KOLOKIUM: Jurnal Pendidikan Luar Sekolah, 7(2), 147-153. https://doi.org/10.24036/kolokium-pls.v7i2.37

Sutawa, G. K. (2012). Issues on Bali Tourism Development and Community Empowerment to Support Sustainable Tourism Development. In Procedia Economics and Finance: nternational Conference on Small and Medium Enterprises Development with a Theme? Innovation and Sustainability in SME Development? (ICSMED 2012) (Vol. 4, pp. 413422). Amsterdam: Elsevier Ltd. https://doi.org/https://doi.org/10.1016/S2212$5671(12) 00356-5$

Wardah, M. W. (2019). Upaya Taman Bacaan Masyarakat (TBM) Ar-Rasyid dalam Pemberdayaan Masyarakat Berbasis Literasi. LIBRIA, 11(1). Retrieved from http://103.107.187.25/index.php/libria/article/download/4989/3288

Yuliyanto, Y., \& Irhandayaningsih, A. (2019). Pemberdayaan Masyarakat Melalui Taman Baca Masyarakat (TBM): Studi Kasus di Desa Pledokan Kecamatan Sumowono Kabupaten Semarang. Anwva: Jurnal Kajian Budaya, Perpustakaan, Dan Informasi, 3(4), 377-386. https://doi.org/10.14710/anuva.3.4.377-386 